\title{
Special issue on digital inclusion
}

\author{
Ram Kumar $^{1} \cdot$ Chandra Subramaniam $^{1} \cdot$ Kexin Zhao $^{1}$ \\ Published online: 12 May 2021 \\ (c) The Author(s), under exclusive licence to Springer-Verlag GmbH Germany, part of Springer Nature 2021
}

Digital inclusion is crucial to promote economic prosperity and social equality. However, gaps persist between individuals, organizations, and communities in their access and use of various digital technologies. In recent days, such inequalities have been exposed globally by the Covid-19 pandemic (Broom 2020), making the investigation of these inequalities more urgent and important. This special issue on digital inclusion aims to develop a better understanding of this important, yet under researched theme in the IS field. Information Systems and e-Business Management (ISeB) is an appropriate venue to publish digital inclusion studies, since the journal focuses on IS management research that advances the field fundamentally and significantly. ${ }^{1}$

Information and communication technologies (ICT) are key infrastructures enabling individuals, organizations, communities, as well as countries to participate in and benefit from today's digital economy. They help people to stay connected, and facilitate the exchange of numerous types of human, natural, financial, health, and social resources. While global Internet penetration rate keeps increasing, the "digital divide" persists, and the ability to access and use ICT effectively remains inequitable (Callahan and Siefer 2019; Newman et al. 2017; Walsham et al. 2007). For instance, recent surveys from Pew Research Center suggest that Internet use varies widely between younger and older people, and people with different levels of education and income (Schumacher and Kent 2020). Even if people can access ICT, their understanding of technology-related issues vary significantly. People with higher levels of education and younger generations tend to be more digitally knowledgeable than their counterparts (Vogels and Anderson 2019). Digital disparities have been observed in the use of healthcare technologies, such as patient online health portal (Walker et al. 2019) and Google's "suicide-prevention result" (Scherr et al. 2019). It is also possible that functionality of digital devices (e.g., smart phones) available to different types of users may create digital inclusion or exclusion, based on factors

\footnotetext{
1 https://www.springer.com/journal/10257/aims-and-scope.
}

Kexin Zhao

kzhao2@uncc.edu

1 Department of Business Information Systems and Operations Management, UNC Charlotte, Charlotte, USA 
such as costs or regulation. Increased use of analytics and artificial intelligence has created new challenges where existing disparities and biases in digital inclusion are reinforced (Park and Humphry 2019). Hence design and innovation that minimizes these disparities are important in the context of digitization (Nambisan et al. 2017). Furthermore, impacts of digital inclusion may not always be positive. For example, the impact of smartphones on children can be unclear (Silver et al. 2019).

It is therefore important to understand this phenomenon of digital inclusion, as well as develop strategies and tactics to promote and enhance digital inclusion, where disadvantaged individuals, groups, and communities can have better access to, and the necessary skills, to use ICT. Digital inclusion can also help address broader socioeconomic inequalities (Newman et al. 2017; Zaffar et al. 2019). Information systems research has made noticeable contributions to understand issues related to digital inclusion. For instance, more than a decade ago, MIS Quarterly devoted a special issue to understand information systems in developing countries (Walsham et al. 2007). More recently, Information Systems Journal launched a combined special issue on social inclusion and digital entrepreneurship (Trauth et al. 2018).

Despite continued research efforts, academia and policy makers face new issues and problems related to digital inclusion, which becomes a complicated and ever evolving challenge faced by the society. ICT develop rapidly, and new digital media, applications, and skills keep emerging. Internet of things, artificial intelligence, and autonomous cars are just a few examples, where new tasks are automated and digitalizedin many sectors. Even the meaning of digital inclusion keeps expanding. For instance, Internet Policy Review organized a special issue asking "what do digital inclusion and data literacy mean today" in August 2019, ${ }^{2}$ highlighting the complex and multi-dimensional nature of this phenomenon. Therefore, we are motivated to edit an ISeB special issue on digital inclusion to further advance IS research in this important area.

We started the process to produce this special issue in February 2020 with the call for papers. We actively promoted the call for papers via multiple venues, including the ISeB website, the AIS mailing list, and various IS researcher communities. In total, we received 13 manuscripts to review. After two rounds of the peer review process, two manuscripts were selected for publication in February 2021, representing a $15.4 \%$ acceptance rate. We editors would like to sincerely thank the reviewers who provided timely and constructive feedback to the manuscripts.

Two papers accepted in this special issue only represent a sample of high-quality research in the broad area of digital inclusion. Both papers have used the survey methodology to understand factors motivating disadvantaged individuals to use digital technologies. They highlight context-dependency of digital inclusion challenges, and propose innovative situational factors moderating the relationships between various drivers and technology use. We briefly review those two papers below. Digital inclusion research can examine issues beyond individual levels, and use a wide range of theories and methodologies. Therefore, future research is still needed to

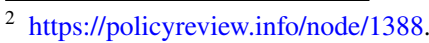


deepen our understanding of digital inclusion, its facilitators, as well as intended and unintended consequences.

Tams et al. (2021) examine the use of mobile technology for work. They focus on the role of age, and collect data from 135 younger and 137 older knowledge workers. Their finding suggests that older workers are more likely to be affected by technology-mediated (T-M) interruptions than younger workers. However, the negative impact of TM interruptions can be reduced by mobile technology experience. Their research provides a nuanced understanding of the generational gap of technology use, and suggests useful mitigation approaches.

Han et al. (2021) investigate the factors critical to adoption of mobile-based social media marketing (SMM) by Chinese farmers. Since consumers of the farm products increasingly use mobile social media platforms to conduct business, explaining the factors that enable Chinese farmers to take part in SMM is a valuable contribution by this paper to the literature on digital inclusion. In their study, the authors focus on the role of product suitability for SMM, gender and age as moderators between the Intention to use SMM and its antecedents. The empirical model is tested with survey data from 313 Chinese farmers, followed by in-depth qualitative interviews with 6 farmers representing family farms and farm co-operatives. Their analysis indicate that gender and age have only limited impacts on the intention to use mobile-based SMM. Product suitability strengthened the relationship between the facilitating conditions and the intention to use SMM. Collectively, these findings show how policy makers can take steps, such as working with digital platform operators, to promote digital inclusion in the larger population.

\section{References}

Broom D (2020) Coronavirus has exposed the digital divide like never before. World Economic Forum, April 22. https://www.weforum.org/agenda/2020/04/coronavirus-covid-19-pandemic-digital-divideinternet-data-broadband-mobbile/

Callahan B, Siefer A (2019) Why smart cities need digital inclusion. 2019. National Digital Inclusion Alliance White Paper. https://www.digitalinclusion.org/wp-content/uploads/2019/10/Smart-Inclu sive-Cities_v1.1.pdf

Han H, Xiong J, Zhao K (2021) Digital inclusion in social media marketing adoption: the role of product suitability in the agriculture sector. Information Systems and e-Business Management, Special Issue on Digital Inclusion

Nambisan S, Lyytinen KJ, Majchrzak A, Song M (2017) Digital innovation management: reinventing innovation management research in a digital world. MIS Q 41(1):223-238

Newman L, Browne-Yung K, Raghavendra P, Wood D, Grace E (2017) Applying a critical approach to investigate barriers to digital inclusion and online social networking among young people with disabilities. Inf Syst J 27(5):559-588

Park S, Humphry J (2019) Exclusion by design: intersections of social, digital, and data exclusion. Inf Commun Soc 22(7):934-953

Scherr S, Haim M, Arendt F (2019) Equal access to online information? Google's suicide-prevention disparities may amplify a global digital divide. New Media Soc 21(3):562-582

Silver L, Smith A, Johnson C, Jiang J, Anderson M, Raine L (2019) Mobile connectivity in emerging economies. Pew Research Center. https://www.pewresearch.org/internet/2019/03/07/mobile-conne ctivity-in-emerging-economies/ 
Schumacher S, Kent N (2020) 8 Charts on internet use around the world as countries grapple with Covid19. Pew Research Center. https://www.pewresearch.org/fact-tank/2020/04/02/8-charts-on-internetuse-around-the-world-as-countries-grapple-with-covid-19/

Tams S, Grover V, Thatcher J, Ahuja M (2021) Grappling with modern technology: interruptions mediated by mobile devices impact older workers disproportionately. Information Systems and e-Business Management, Special Issue on Digital Inclusion

Trauth E, Joshi KD, Yarger LK (2018) ISJ editorial-combined special issues on social inclusion and digital entrepreneurship. Inf Syst J 28(6):989-994

Vogels EA, Anderson M (2019) Americans and digital knowledge. Pew Research Center. https://www. pewresearch.org/internet/2019/10/09/americans-and-digital-knowledge/

Walker DM, Hefner JL, Fareed N, Huerta TR, McAlearney AS (2019) Exploring the digital divide: age and race disparities in use of an inpatient portal. Telemed e-Health. https://doi.org/10.1089/tmj. 2019.0065

Walsham G, Robey D, Sahay S (2007) Forward: special issue on information systems in developing countries. MIS Q 31(2):317-326

Zaffar A, Kumar RL, Zhao K (2019) Using agent-based modelling to investigate diffusion of mobilebased branchless banking services in a developing country. Decis Support Syst 117:62-74

Publisher's Note Springer Nature remains neutral with regard to jurisdictional claims in published maps and institutional affiliations. 